\title{
Maggots on the brain (and in it)
}

\author{
A case of cerebral myiasis \\ Craig Olmstead (Meds 2017), Charles Jian (Meds 2018) \\ Faculty Reviewer: Dr Michael John, MD, FRCPC (Division of Infectious Diseases)
}

\section{INTRODUCTION}

In the aftermath of a traffic collision, it can be common for emergency responders to find the victims disoriented, confused, or even aggravated. Often, this is the result of the psychological or physical trauma sustained during the collision. ${ }^{1}$ On occasion, any number of prior medical conditions may be contributing to a victim's altered mental status. These may even be the primary cause for their presentation, complicating the situation for both the initial responders and emergency room medical staff. ${ }^{2}$ Our case begins in just such a fashion. After a low-velocity collision, a 75-year-old Californian man was found behaving erratically and aggressively by emergency responders. Responders diligently removed the patient's hat to check for injuries. Under the hat was not an injury related to blunt trauma sustained during the collision, as one might expect, but rather a lesion with exposed cerebral matter which contained a clear infestation by maggots. The patient was subsequently brought to the emergency room for further investigation. ${ }^{3}$

While simple lesions of the scalp are often benign, resulting from minor trauma or common dermatological conditions, lesions which perforate the skin, bone, and meninges such as the one seen in our case are quite rare. ${ }^{4}$ Penetrating head injuries, neoplastic conditions and severe cranial infections are the most likely suspects. ${ }^{3,5,6}$ In the case of penetrating head injuries, gunshot wounds, stabbings, and motor vehicle collisions are the most prevalent. ${ }^{5}$ Possible neoplastic conditions include osteoma or osteosarcoma of the cranial bones, hemangioma, and angiosarcoma. ${ }^{3,6,7}$ Potential cranial infections include brain abscesses due to bacterial or fungal infections. ${ }^{8}$

\section{CASE PRESENTATION \& DIAGNOSIS}

Investigation continued at the hospital with a patient history provided by family members. The lesion had started as a reddish-purple nodule on the frontal scalp. Over the course of a year, it had expanded, ulcerated, and ultimately become infested with maggots. Although various family members had advised treatment for the nodule, the patient had refused, citing religious reasons. The patient resided with his wife, who had been diagnosed with advanced Alzheimer's, and his contact with the rest of his family was infrequent. Additionally, later investigations revealed extremely poor living conditions, exemplified by garbage accumulation, animal fecal matter, and the presence of rodents. These factors allowed the lesion erosion and subsequent infestation to develop undetected until the collision. ${ }^{3}$

On physical examination, the patient displayed obvious poor hygiene and presented with a strong putrid odour. The patient's vital signs and temperature were unremarkable. The cranial lesion was examined in detail. It presented with substantial erosion, measuring $15 \mathrm{~cm} \times 17 \mathrm{~cm}$, and extended bilaterally over the frontal cranial region from the orbital rim to the parietal scalp. Within the lesion the dura was absent, exposing cerebral brain tissue. Two cortical defects were found around the midline of the lesion, each of which contained dense clusters of live maggots embedded within the brain tissue. A count of the number of live maggots was deemed impractical and not performed. The maggots engaged in active movement in all regions of the defect, including the surface of the exposed cerebral tissue. ${ }^{3}$

The patient remained conscious but torpid, and responded to simple commands. Further neurological examination was normal. A complete blood count and white blood cell differential was performed, revealing a WBC count of $20100 / \mathrm{mm}^{3}, 91 \%$ neutrophils and no bands. Blood culture in the emergency room indicated the presence of penicillin-sensitive group G Streptococcus. ${ }^{3}$

Finally, a computerized tomography scan identified multiple skeletal and abdominal lesions, including a destructive soft tissue mass in the left posterior chest wall. This mass was centered at the T9 vertebral body and extended into the spinal canal. Needle biopsies of the lesion sites revealed poorly differentiated spindle-shaped CD31-, CD34-positive cells. Additionally, the patient had swollen parotid glands, which also tested positive for the same cell types. These finding supported a diagnosis of metastatic angiosarcoma. ${ }^{3}$

\section{MANAGEMENT}

The patient was admitted to intensive care. Broad-spectrum antibiotics were started, specifically a regimen of intravenous vancomycin, ceftriaxone, and metronidazole. Maggot extraction was moderately successful, and was performed via gentle suction. The remaining maggots were covered with sterile surgical dressings soaked in a mild bleach solution. No living maggots remained after 3 days. $^{3}$

Psychiatric evaluation determined the patient competent to make his own medical decisions. The patient declined any surgery and any treatments for his metastatic angiosarcoma. The family as well as the ethics committee upheld his decision. Because he declined surgery, the cortex remained exposed following treatment, until his death 3 months later following his transfer to a nursing facility. ${ }^{3}$

\section{DISCUSSION}

Cerebral myiasis is an exceedingly rare condition, with only a handful of described cases worldwide. The vast majority of these cases have been identified postoperatively. All reported cases which state an outcome have unfortunately resulted in death of the patient, although the cerebral myiasis may not have been a main con- 
tributor to their deaths. In this case, the more immediate threat was likely the presence of group G $\beta$-hemolytic Streptococcus, which can present indistinguishably from a group A streptococcal infection, while the ultimate cause of death was presumably due to the untreated metastatic angiosarcoma. ${ }^{3,9}$ Indeed, without the open cranial lesion caused by the angiosarcoma, the maggot infestation would have likely been self-limiting; the short lifecycle of the fly species discovered (Phaenicia sericata, commonly called the green bottle fly) would have resulted in the elimination of live maggots within a week or so without continuous deposition of new eggs by adult flies. ${ }^{3,10}$

With the exception of the case presented here, all have occurred outside North America. Reported cases of cerebral myiasis indicated lesions which were less extensive than the one seen in this case. The presence of angiosarcoma as the primary cranial lesion could have contributed to the extent of the infestation. Maggots of the common green bottle fly preferentially feed on dead tissue, and have been used in maggot therapy to debride away dead tissue. In this case, tumor growth may have continuously provided necrotic material to sustain the maggots. ${ }^{3,10,11}$

As there have been so few cases of cerebral myiasis, no standard treatment exists. Removal of the maggot infestation, as was conducted in this case, would seem to be an appropriate course of action. Broad spectrum antibiotics to treat concurrent bacterial infections and ward off secondary infection would also appear to be prudent, particularly as the presence of Phaenicia sericata larvae may help protect against bacterial infections, a protection that may be removed with the elimination of the infesting maggots. ${ }^{3,11}$ Evaluation of mental status should be undertaken to determine the extent of cognitive impairment, if any, and to establish competence to direct care. ${ }^{3}$

\section{CONCLUSION}

This is an extremely unlikely case of cerebral myiasis that has invaded through the meninges. That this case was identified only after evaluation after a low-speed collision, and that cognitive function was still largely intact is truly remarkable given the extent of the infestation. In medicine, we are told that when we hear hoof beats, we should think horses, not zebras, and certainly not fictional unicorns. This first reported case of cerebral myiasis in North America with its highly improbable presentation is about as close to a unicorn as we come in modern medicine.

\section{REFERENCES}

1. Bush SS, Myers TE. Neuropsychological services following motor vehicle collisions. Psychol Inj Law. 2013 Mar;6(1):3-20.

2. Carroll LJ, Rothe JP. Viewing vehicular violence through a wide angle lens: contributing factors and a proposed framework. Can J Criminol Crim. 2014 Feb;56(2):149-66.

3. Cheshier SH, Bababeygy SR, Higgins D, Parsonnet J, Huhn SL. Cerebral myiasis associated with angiosarcoma of the scalp: case report. Neurosurgery. 2007 Jul;61(1):e167.

4. Lloret I, Server A, Taksdal I. Calvarial lesions: a radiological approach to diagnosis. Acta Radiol. 2009;50(5):531-42.

5. Santiago LA, Oh BC, Dash PK, Holcomb JB, Wade CE. A clinical comparison of penetrating and blunt traumatic brain injuries. Brain Inj. 2012 Feb;26(2):107-25.

6. Cihan YB, Kaplan B, Deniz K, Domnez H. Primary calvarial osteosarcoma: a case report. J Neurol Sci. 2012;29(1):122-8.

7. Mendenhall WM, Mendenhall CM, Werning JW, Reith JD, Mendenhall NP. Cutaneous angiosarcoma. Am J Clin Oncol. 2006 Oct;29(5):524-8.

8. Anslow P. Cranial bacterial infection. Eur Radiol. 2004 Mar;14(3):e145-54.

9. Brandt CM, Spellerberg B. Human infections due to streptococcus dysgalactiae subspecies equisimilis. Clin Infect Dis. 2009 Sept;49(5):76672.

10. Lucilia sericata (Common Green Bottle Fly) [Internet]. La Crosse (WI): University of Wisconsin-La Crosse; c2006. Reproduction; c2006 [cited 2015 Feb 2]. Available from http://bioweb.uwlax.edu/ bio203/2011/stutz_jenn/reproduction.htm

11. Jaklic D, Lapanje A, Zupancic K, Smrke D, Gunde-Cimerman N. Selective antimicrobial activity of maggots against pathogenic bacteria. $\mathrm{J}$ Med Microbiol. May 2008;57(5):617-25. 